\title{
Impact Factors and Other Rey Wetrites Released for All Six TMS Journals
}

\section{Matt Baker and Kelly Zappas}

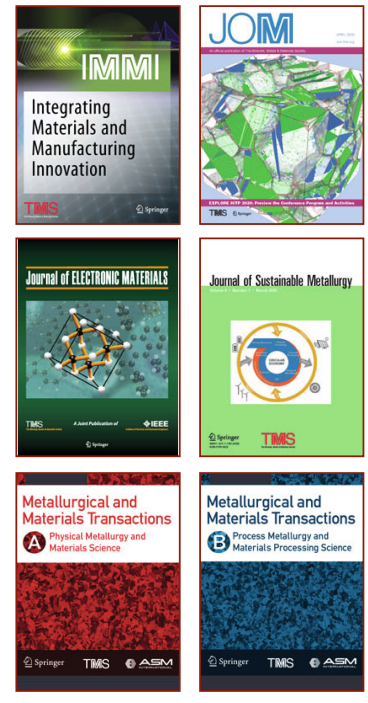

"This year's release marks the first Impact Factors for Integrating Materials and Manufacturing Innovation (IMMI) and Journal of Sustainable Metallurgy (JSM), both of which achieved strong debut numbers."
The 2019 Journal Citation Reports (Clarivate Analytics, 2020) were released in late June and included Impact Factors for all six TMS journals. This year's release marks the first Impact Factors for Integrating Materials and Manufacturing Innovation (IMMI) and Journal of Sustainable Metallurgy (JSM), both of which achieved strong debut numbers. The following list shows the 2019 Impact Factors for each TMS journal, with a comparison to 2018 in parentheses for journals that received an Impact Factor for that year:

- Integrating Materials and Manufacturing Innovation: 3.447 (n/a)

- JOM: 2.029 (2.305)

- Journal of Electronic Materials: 1.774 (1.676)

- Journal of Sustainable Metallurgy: 2.109 (n/a)

- Metallurgical and Materials Transactions A: 2.05 (1.985)

- Metallurgical and Materials Transactions B: 2.035 (1.952)

The success of TMS's two newest journals reflects the changing landscape of materials science and engineering, according to Judy Schneider, TMS
Director/Chair, Content Development \& Dissemination and Professor, University of Alabama at Huntsville.

"IMMI explores innovations that build on integrated computational materials engineering (ICME), from the discovery of materials through their manufacture," said Schneider. "The journal reflects the convergence of several research fields toward the goal of accelerating discovery through multi- and interdisciplinary research areas. A complement to accelerated discovery is the consideration of sustainability of metal-producing industries, with an emphasis on materials recovery, reuse, and recycling. For these efforts, JSM captures the emerging research."

A journal's Impact Factor is the average number of citations counted in a given Impact Factor year for articles published in the two preceding years. It is based on the number of citations of a journal's content divided by the number of citable articles published by that journal. Impact Factor is just one of many factors to consider when evaluating journal performance. The Impact Factor is a measure of the impact of a journal, and not of the quality of the published research.

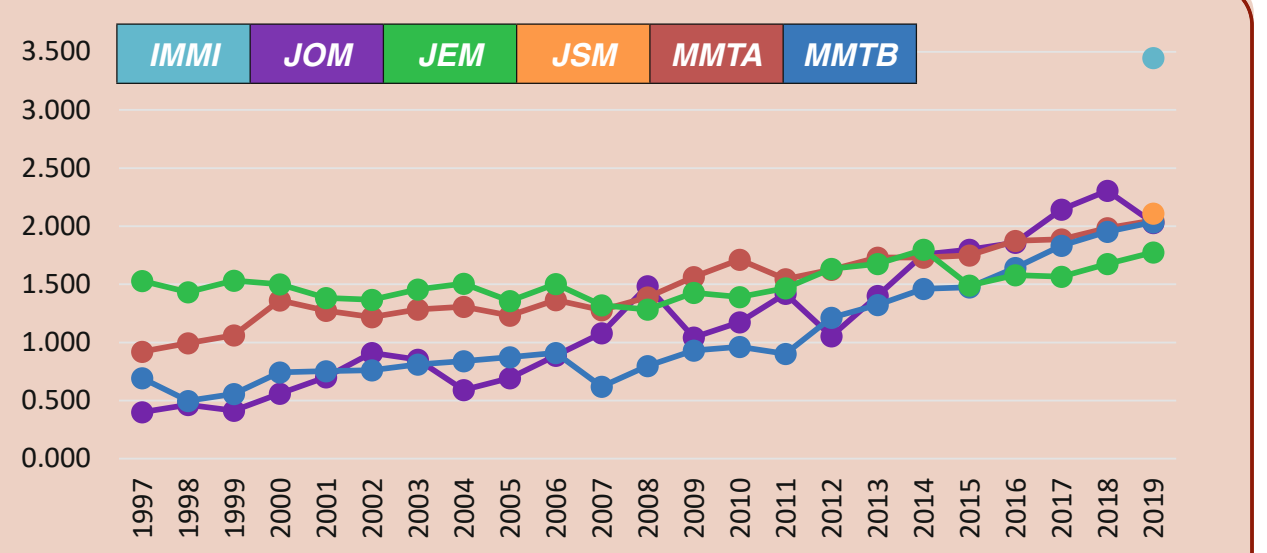

Figure 1. Impact Factors for TMS journals since 1997. 
While Impact Factor can vary from year to year for a variety of reasons, TMS journals have generally tracked in a positive direction (see Figure 1 on previous page), and have also achieved strong placement in Clarivate's ranking by subject categories (see Table I).
Table II shows a more comprehensive overview of 2019 key metrics across the entire TMS journal portfolio. It is worth noting that Metallurgical and Materials Transactions $A$ had the most total citations $(30,270)$ and the most total downloads $(934,975)$ among TMS journals.

Table I. This table presents the subject categories assigned to TMS journals, and the rank of the journals within these categories.

\begin{tabular}{|l|c|c|c|c|c|c|c|}
\multicolumn{1}{|c|}{ Category Name } & $\begin{array}{c}\text { 2019 Total } \\
\text { Journals }\end{array}$ & IMMI & JOM & JEM & JSM & MMTA & MMTB \\
\hline Materials Science, Multidisciplinary & 314 & 112 & 192 & 216 & - & 188 & 190 \\
\hline Metallurgy \& Metallurgical Engineering & 79 & - & 23 & - & 19 & 21 & 22 \\
\hline Mineralogy & 30 & - & 12 & - & - & - & - \\
\hline Mining \& Mineral Processing & 21 & - & 8 & - & - & - & - \\
\hline Engineering, Electrical \& Electronic & 266 & - & - & 157 & - & - & - \\
\hline Physics, Applied & 154 & - & - & 92 & - & - & - \\
\hline Green \& Sustainable Science \& Technology & 41 & - & - & - & 30 & - & - \\
\hline Engineering, Manufacturing & 50 & 17 & - & - & - & - & - \\
\hline
\end{tabular}

Table II. This table shows 2019 key metrics—five-year Impact Factor, total citations, and total downloads-for TMS journals in addition to their Impact Factors.

\begin{tabular}{|l|c|c|c|c|c|c|}
\cline { 2 - 7 } \multicolumn{1}{c|}{} & IMMI & JOM & JEM & JSM & MMTA & MMTB \\
\hline 2019 Impact Factor & 3.447 & 2.029 & 1.774 & 2.109 & 2.05 & 2.035 \\
\hline Five-Year Impact Factor & - & 2.717 & 1.619 & - & 2.244 & 2.248 \\
\hline Total Cites 2019 & 479 & 10,345 & 12,786 & 551 & 30,270 & 9,636 \\
\hline Total Downloads 2019 & 61,609 & 636,629 & 306,836 & 82,223 & 934,975 & 368,346 \\
\hline
\end{tabular}

To access TMS's entire library of journals, visit the Journals section of the TMS website at www.tms.org/Journals. (TMS members should log in to the TMS website before clicking on the individual journal links to ensure full access to content.)
Visit the journal home pages on the Springer website (accessible through the TMS Journals website) to view a range of 2019 key metrics including Impact Factors. 